\title{
Kollektive literarische Praxis in Wien um 1770
}

\author{
Michael Denis und die Jugendfrüchte des k. k. Theresianum
}

\author{
Thomas Assinger
}

\section{Einleitung}

In Literaturgeschichten gilt die maria-theresianische Epoche als eher schwerfällige Frühphase der Ausbildung einer deutschsprachigen literarischen Kultur in Österreich. Im Ablösungsprozess der kulturellen Hegemonie lateinischer Traditionen waren erst mit der vollständigen Übernahme der Regierungsgeschäfte durch Joseph II. die Voraussetzungen einer dominant deutschsprachigen Entwicklung günstig, was in den 178 oer Jahren zu einer schlagartigen Freisetzung schriftstellerischer Energien und zur allmählichen Etablierung moderner literarischer Institutionen führte. ${ }^{1}$ Vor diesem Hintergrund ist die Publikation der Jugendfrüchte des $k . k$. Theresianum bemerkenswert. Die Jugendfrüchte sind drei Sammlungen literarischer Kurztexte in deutscher Sprache, die $177^{2}$ und 1774 im Druck erschienen. ${ }^{2}$ Geschrieben wurden die Texte von adeligen Zöglingen jener Wiener Erziehungs- und Bildungsanstalt, an der "der berühmte Dichter Michael Denis“, ${ }^{3}$ der mit seiner Ossian-Übersetzung und mit seiner kriegs- und bardenlyrischen Produktion im gesamten deutschen Sprachraum Beachtung fand, die ,schönen Wissenschaften' lehrte. Diese publizistische Unternehmung wird im Folgenden als Teil einer literarischen Praxis kontextualisiert, die seit Anfang der 176oer Jahre unter Maßgabe von Denis am Theresianum betrieben wurde. Mit der institutionell eingehegten Praxis formierte sich ein konkurrenzlogisch organisiertes Produktionskollektiv, das durch die Vervielfältigung literarischer

1 Vgl. zur Übersicht Herbert Zeman, „Die österreichische Literatur im Zeitalter Maria Theresias und Josephs II.", in: ders. (Hrsg.), Literaturgeschichte Österreichs von den Anfängen im Mittelalter bis zur Gegenwart, 2., überarb. und aktual. Aufl., Freiburg/Br. u.a.: Rombach 2014, S. 325-384.

2 Jugendfrüchte des k. k. Theresianum. Erste Sammlung, Wien:Kurzböck 1772;Zweyte Sammlung, Wien: Kurzböck 1772; Dritte Sammlung, Wien: Kurzböck 1774. Band- (römische Ziffern) und Seitenangaben (arabische Ziffern) in Klammern im Text weisen sämtlich Zitate aus den Jugendfrüchten nach.

3 Friedrich Nicolai, Beschreibung einer Reise durch Deutschland und die Schweiz, im Jahre 1781. Nebst Bemerkungen über Gelehrsamkeit, Industrie, Religion und Sitten, Bd. 4, Berlin, Stettin: Nicolai 1784 , S. 783 . 
Gattungsoptionen auch außerhalb der Schule kulturelle Wirkung auf die Entwicklung deutschsprachiger Literatur in Österreich entfalten sollte.

\section{Text}

„Als ich jüngst nach der Mittagszeit Ciceros Reden in die Hand nahm, überfiel mich ein Schlaf. Ich widerstand einige Minuten, endlich fiel mir das Buch aus den Händen, und mein Haupt sank auf mein Schreibpult." (I, S. 1f.) Mit dieser missglückenden Leseszene setzt eine didaktische Erzählung aus den Jugendfrüchten des $k . k$. Theresianum ein. Unter der Überschrift Das Reich der Beredsamkeit in einem Traume wird die zu vermittelnde Materie - wenig überraschend und doch plötzlich - in einer Traumsequenz aufbereitet:

[...] und mein Haupt sank auf mein Schreibpult. In diesem Augenblicke sah ich einen ehrwürdigen Mann vor mir. Ich erschrack, weil er mir unbekannt schien. Ein frisches Grau zierte sein Haupt. Hoheit mit Annehmlichkeit vermengt beherrschte sein Antlitz. Sein Blick glich jenem des Adlers, wenn er zur Sonne aufschaut. In der rechten Hand hielt er ein Buch. Mit der linken hatte er eine römische Toga zusammen gefasset. (I, S. 2)

Noch der letzte Zweifel an der Identität des mit Buch und Toga bewehrten „ehrwürdigen Mann[es]" wird zerstreut, wenn dieser selbst sich in direkter Rede an den Ich-Erzähler wendet und ihn über den Grenzübertritt in die Traumdiegese aufklärt: „Ich bin jener, den du wachend in der Hand hieltest. Ich bin Cicero.“ (I, S. 3)

Das träumende Ich wird von der antiken Autorität nun durch das Reich der Beredsamkeit geführt hin zum Tempel von Suada, Göttin der Überredung und Herrscherin über den Bezirk der ars rhetorica. Das Verhältnis zwischen den beiden Wanderern wird von Cicero klar bestimmt: „Fürchte nichts, o Jüngling! wir folgen einem Beruffe. Du bist ein Anfänger, ich ein Meister. Wir dienen einer Gottheit." (I, S. 2) So gewinnt auch das Ich der Erzählung Kontur als Schüler der Beredsamkeit. Auf dem Weg zu Göttin Suada werden dem Träumer in einprägsamer top(olog)ischer Ordnung und allegorischer Einkleidung Grundbegriffe der Systemrhetorik vorgeführt: Zunächst sind auf "zwey unabsehbare[n] Felder[n] " „alle Wörter" und „alle Dinge“ versammelt (I, S. 4f.). Es begegnen die Perioden (I, S. 5), später Tropen und Figuren (I, S. 15), in Suadas Tempel schließlich Beweise und Örter (I, S. 16), Affekte und Laster (I, S. 19). Darüber hinaus sieht der Schüler jene schrecklichen und lieblichen Orte, zu denen die missbräuchliche bzw. tugendhafte Verwendung dieser Kunst nach dem Tod führt. Diejenigen, die sich Vergehen gegen die Kunstfertigkeit 
der ars bene dicendi, aber auch gegen die moralische Verpflichtung des Redners zum vir bonus schuldig gemacht haben, leiden infernalische Qualen, säuberlich getrennt nach Typ der beredten Missetat. Dagegen erfreuen sich die vorbildlichen Redner aus Antike und Neuzeit paradiesischer Ewigkeit.

An einer Weggabelung, nicht weit vom Palast der Göttin, tritt die Nymphe Nachahmung an die Wanderer heran. Sie setzt dem Träumer auseinander, dass zwei Wege zum „Wohnsitz unserer Herrscherinn“ (I, S. 13) führen: "Jener ist aber länger, dieser viel kürzer; durch jenen führen uns die Regeln, durch diesen die Beyspiele. Wir wollen dem kürzeren folgen." (I, S. 14) Der Weg der Beispiele ist eingefasst von Marmorwänden, in die die Reden Ciceros geätzt sind. Trotz "heilige[r] Furcht" und anfänglichem "Schauer" (I, S. 15) ist die Begegnung ein voller Erfolg für das Ich der Erzählung. Die didaktische Richtschnur zur Meisterschaft mit den Wörtern und den Dingen wird gespannt. Der Weg dorthin sei zwar beschwerlich, aber der Ruhm der Unsterblichkeit dem, der ihn gehe, gewiss. Abschließend spendet die Göttin mahnende Worte pädagogischer Motivation:

Auch du, o Jüngling! Suche auf dieser Bahn der Ehre deinen Namen zu vergrößern, und das Lob deiner Nachkömmlinge zu verdienen. Nur laß die Tugend von dir nicht weichen, folge der Vernunft, und gieb nicht zu, daß sich Weichlichkeit, oder Trägheit bey dir einschleiche. Also sprach die Göttinn. Als ihr [sic!] ihr eben antworten wollte, hörte ich zur Schule läuten, und ward wache. (I, S. 22)

Verfasser dieser literarischen Begehung des Reichs der Beredsamkeit in einem Traume ist der jugendliche Franz Xaver Graf von Auersperg. ${ }^{4}$ Zum Zeitpunkt der Ausarbeitung in der zweiten Hälfte der 176oer Jahre erhält er „Unterricht in der Schönen Literatur" (I, Vorbericht, unpag.) am Theresianum in Wien. Ein zentraler Lehrinhalt, den die Erzählung vermittelt, dass nämlich der effektivste Weg zu oratorischer und ethischer Perfektion (für die Alten zum vir bonus dicendi peritus; für die Neueren eher zur docta et eloquens pietas) über die Nachahmung vorbildlicher Beispiele verläuft, ist vom Text selbst umgesetzt. Das erschließt sich aus seiner Genese. Es handelt sich um die deutsche Prosaauflösung eines neulateinischen Lehrgedichts in Hexametern, das der Jesuit Michael Denis 1753 in Klagenfurt geschrieben hatte. ${ }^{5}$ Die Kombination von

4 In den Jugendfrüchten steht „Auersberg“; in der institutionellen Dokumentation lautet die Schreibung (recte) „Auersperg“.

5 Michael Denis, „Palatium rhetoricae“, in: ders., Michaelis Denisii Carmina quaedam, Wien: Albert 1794, S. 112-131. Vgl. dazu Fritz Keller, „Rhetorik in der Ordensschule. ,Palatium rhetoricae‘ von Michael Denis: Ein didaktisches Epos - seine literarische Tradition, künstlerische Gestaltung und sein Verhältnis zum zeitgenössischen Rhetorikunterricht bei den Jesuiten“, in: Herbert Zeman (Hrsg.), Die Österreichische Literatur. Ihr Profil an der Wende 
Übersetzung und Prosaparaphrase, die den Prozess der Textproduktion strukturiert, ist als spezifische Übungspraktik im frühneuzeitlichen Dispositiv rhetorischer und poetischer Ausbildung fest etabliert. Für derartige Schreibübungen ist bereits in der antiken Rhetoriklehre das methodische Prinzip der imitatio konstitutiv. ${ }^{6}$ Der Schüler setzt nicht einfach Regeln eines Lehrgebäudes der Rede- oder Dichtkunst in eigenständige Texte um, sondern ahmt unter Berücksichtigung der erlernten Theorie mustergültige Texte nach. ${ }^{7}$ Diese Einübung rhetorischer Kunstfertigkeit durch die Praxis der imitatio auctoritatis entspricht beinahe passgenau jener allegorisch-vorgestellten Route, den die Nymphe Nachahmung im Reich der Beredsamkeit für eine Karriere zum vollkommenen Redner empfiehlt. Allein die strukturell notwendige Funktion normativer Theorie gerät der Erzählung nach der Weggabelung zwischen „Regeln“ und „Beyspiele[n]“ angesichts der vollendeten Reden Ciceros aus dem Blick. ${ }^{8}$

vom 18. zum 19. Jahrhundert (1750-1830), Graz: Akademische Druck- und Verlagsanstalt 1979, S. 55-83; dort finden sich Erläuterungen von Bezügen zur Barockallegorie und zu antiken Entsprechungen der rhetorischen Inhalte. Eine Interpretation, die vor dem Hintergrund literarischer Bezugstexte - insbesondere und offenkundig Dantes Divina Commedia - auf "die ethische und religiöse Dimension des jesuitischen eloquentia-Ideals" im Text abhebt, unternimmt Elisabeth Klecker, „Das Palatium Rhetoricae des Michael Denis: Ein jesuitisches Lehrgedicht über die Redekunst und seine literarische Tradition“, in: Wolfgang Kofler und Karlheinz Töchterle (Hrsg.), PONTES III. Die antike Rhetorik in der europäischen Geistesgeschichte, Innsbruck u.a.: StudienVerlag 2005, S. 304-317, hier S. 315 .

6 Zur Systematisierung der rhetorischen Übungen in exercitationes legendi, audiendi, scribendi und dicendi sowie zu deren Ausrichtung auf imitatio vgl. das Kapitel „Die Übung (askesis, melete/exercitatio, usus)“, in: Gert Ueding und Bernd Steinbrink, Grundriß der Rhetorik. Geschichte - Technik - Methode, 5., aktual. Aufl., Stuttgart, Weimar: Metzler 2011, S. 329-333.

7 Dies lässt sich insgesamt für literarische Kulturen geltend machen, deren Textproduktion von normativer Rhetorik und Poetik geprägt ist. Es wäre ein mechanistischer Kurzschluss, von einer nicht durch andere literarische Texte vermittelten direkten Applikationslogik auszugehen. Denn: „Rhetorik als Disziplin [...] beruht [...] nicht auf einer Zweiheit von doctrina und elaboratio, sondern auf der Dreiheit von doctrina (bzw. praecepta), exempla und imitatio" (Wilfried Barner, Barockrhetorik. Untersuchungen zu ihren geschichtlichen Grundlagen, 2. Aufl., Tübingen: Niemeyer 2002, S. 59). Hinzu kommt die von Rhetorik und Poetik in der Regel systemimmanent vorgesehene Möglichkeit der licentia.

8 Die narrative Setzung der Alternative Regel/Beispiel bemüht einen Gemeinplatz der lateinischen Bildungsgeschichte. Seneca legt in einer Briefstelle die Vorzüge von Exemplarizität im Umgang mit vorbildlichen Menschen im Gegensatz zu Vorschriften für die moralische Vervollkommnung des Selbst dar: „Plus tamen tibi et viva vox et convictus quam oratio proderit; in rem praesentem venias oportet, primum quia homines amplius oculis quam auribus credunt, deinde quia longum iter est per praecepta, breve et efficax per exempla“ (Lucius Annaeus Seneca, Epistulae morales ad Lucilium / Briefe an Lucilius über Ethik, hrsg. von Marion Giebel, Stuttgart: Reclam 2014, Teil 1, S. 32, Epist. I, 6, 5). In der Rezeption wird der Passus auf die abschließende Begründung reduziert und zur deklarativen 


\section{Institution}

Michael Denis, ${ }^{9}$ die nachgeahmte literarische Autorität, hatte nach dem Noviziat in der Gesellschaft Jesu in den 175oer Jahren seine Bewährungstour als Grammatik- und Rhetoriklehrer durch die österreichische Ordensprovinz angetreten. Zum Ende des Jahrzehnts wurde er an das Wiener Theresianum berufen. ${ }^{10}$ Das jesuitisch geführte Collegium Regium Theresianum war ${ }^{1746}$ unter kaiserlicher Gunst eröffnet worden. Als Ritterakademie (Collegium nobilium) war es einerseits eine Institution der adeligen Habitusformierung für die Söhne des erbländischen Adels; andererseits bereitete es im Verbund mit den Neugründungen der Theresianischen Militärakademie in Wiener Neustadt (1751) und der Akademie der Orientalischen Sprachen (1753) zukünftige Funktionseliten auf ihre administrativen, militärischen und diplomatischen Karrieren im Staatsdienst vor. ${ }^{11}$ Denis führte seine dortige Lehrtätigkeit bis zur Aufhebung des Ordens 1773 fort. Danach wurde er mit der Leitung der hauseigenen Garellischen Bibliothek betraut, ${ }^{12}$ bis es $1783 / 84$ zur vollständigen

Sentenz verallgemeinert. Senecas auctoritas bürgt so für die Veranschaulichung rhetorischer Schulungsoptionen im Zwei-Wege-Modell. In ihrer konzeptuellen und praktischen Komplexität ist rhetorische Ausbildung damit allerdings nicht adäquat ins Bild gesetzt.

9 Vgl. zu Denis nach wie vor Paul von Hofmann-Wellenhof, Michael Denis. Ein Beitrag zur deutsch-oesterreichischen Literaturgeschichte des XVIII. Jahrhunderts, Innsbruck: Wagner'sche Universitäts-Buchhandlung 1881.

10 In der Forschung sind unterschiedliche Datierungen von Denis' Berufung nach Wien im Umlauf. Die Administration der Gesellschaft Jesu verzeichnet ihn erstmals 1760 am Theresianum, wohin er lt. eigener Angabe im Oktober 1759 gekommen war, in erzieherischer Funktion als praefectus; ab 1761 als professor rhetoricae; und weiterhin dann als professor rhetoricae et linguae germanicae (ab 1763/64), als professor rhetoricae et eloquentiae germanicus (1771) und als professor litterarum elegantium (1773). Ladislaus Lukács (Hrsg.), Catalogi Personarum et Officiorum Provinciae Austriae Societatis Iesu, Bd. IX (1748-176o), Rom: Institutum Historicum Societatis Iesu 1994; Bd. X (1761-1769) und Bd. XI (1770-1773), Rom 1995 .

11 Vgl. Ivo Cerman, „Habsburgischer Adel und das Theresianum in Wien 1746-1784 (Wissensvermittlung, Sozialisation und Berufswege)“, in: Ivo Cerman und Luboš Velek (Hrsg.), Adelige Ausbildung. Die Herausforderungen der Aufklärung und die Folgen, München: Meidenbauer 2006, S. 143-168, hier S. 165-168; sowie Ivo Cerman, Habsburgischer Adel und Aufklärung. Bildungsverhalten des Wiener Hofadels im 18. Jahrhundert, Stuttgart: Steiner 2010, S. 219-242. Zur Geschichte des Hauses allgemein vgl. Eugen Guglia et al., Die Theresianische Akademie, Wien: Eigenverlag der Stiftung,Theresianische Akademie' 2015. Einen ordensgeschichtlichen Fokus zur Ergänzung bietet Bernhard Duhr, Geschichte der Jesuiten in den Ländern deutscher Zunge, Bd. 4,1, München, Regensburg: Manz 1928, S. $35^{8}-365$.

12 Die Datierungen von Denis' Funktionsperiode als Bibliothekar sind in der Forschung wiederum uneinheitlich. Die Catalogi Personarum, Bd. XI (Anm. 10), S. 264, nennen ihn 
Schließung der Einrichtung kam. Franz Xaver Graf von Auersperg war von 1759-1768 als Zögling am Theresianum inskribiert. ${ }^{13}$ Zwar ist aufgrund der Überlieferungslage nicht zu konkretisieren, ob und wann genau er bei Denis studierte, doch wird die deutsche Paraphrase des Palatium rhetoricae im institutionell abgesteckten Rahmen des Literaturunterrichts am Theresianum entstanden sein.

Noch bevor der Lehrbetrieb am 3. November 1746 aufgenommen wurde, war die Broschüre Idea Collegii Regii Theresiani im Druck erschienen, die einen übersichtlichen Entwurf der neuen Ausbildungs- und Erziehungseinrichtung für die adelige Klientel bot. ${ }^{14}$ Darin kommt der konzeptionelle Doppelcharakter der Institution als Anstalt in der jesuitischen Tradition des lateinischen Bildungswesens und als staatliche Agentur zur zeitgemäßen Elitenausbildung zur Geltung. Die Einteilung des Unterrichts in Klassenstufen mit zugeordneten Fächern ist an der standardisierten Organisationsform der Jesuitenkollegien orientiert, die in der Ratio studiorum international verbindlich festgeschrieben ist. ${ }^{15}$ Ein Zögling durchläuft demgemäß zuerst in fünf Jahren die studia inferiora des Gymnasiums (Grammatica infima, media, suprema, Humanitas/ Poesis, Rhetorica) und absolviert dann den zweijährigen philosophischen Studiengang des Lyceums. Darauf aufbauend sieht das Theresianum hingegen kein theologisches Studium, sondern ein dreijähriges Studium der Rechte vor und zielt damit auf praktischen Nutzen für die Absolventen. ${ }^{16}$

ab 1771 in der Funktion als socius praefecti bibliothecae Garellianae; ab 1773 als praefectus bibliothecae Garellianae.

13 Vgl. Max Freiherr von Gemmell-Flischbach (Hrsg.), Album des k. k. Theresianums (1746-1880), Wien: Moritz Perles 1880, S. 31, Nr. 367.

14 Idea Collegii Regii Theresiani quod sub gloriosissimis auspiciis, jussuque clementissimo Mariae Theresiae Augustissimae Romanorum Imperatricis, Gloriosissime Regnantis Hungariae, \& Bohemiae Reginae pro Nobilium Educatione sub cura patrum Societatis Jesu Viennae erectum est. o.O. 1746.

15 Den kritischen Text bietet Ladislaus Lukács (Hrsg.), Ratio atque institutio studiorum Societatis Jesu (1586, 1591, 1599), Rom: Institutum Historicum Societatis Iesu 1986.

16 Das erschließt sich direkt aus den Unterrichtsgegenständen: „Philosophiam egressis tradetur Jus Naturae, \& Gentium, uti \& Romani Juris Historia, Institutiones praeterea, Digesta, Jus Codicis, Feudale, \& Canonicum trium annorum decursu praelegentur, quo etiam tempore in Historia, Geographia, \& Genealogia Patria perficere se quisque studebit" (Idea Collegii Regii Theresiani [Anm. 14], S. VI). Der Fächerkanon insgesamt wird um eine Reihe von Spezialfächern ergänzt: neben Universalgeschichte, europäischer, deutscher, ungarischer und böhmischer Geschichte u.a. um die jeweils entsprechende Geographie, Genealogie und Heraldik, Arithmetik sowie - standesgemäß - die Tanz-, Waffen- und Reitkunst (vgl. ebd., S. VII). 
Der literarische Unterricht ist mit lateinischer Grammatik, Poesie und Rhetorik für die ersten fünf Schuljahre konventionell strukturiert. Die Unterrichtsmethoden und -ziele sind primär auf Fertigkeiten in schriftlicher und mündlicher Textproduktion ausgerichtet. ${ }^{17}$ Poesie und Rhetorik sind im jesuitischen eloquentia-Ideal literarischer Bildung zwar notwendig aufeinander verwiesen; doch wird am Theresianum der Rhetorik der Vorrang eingeräumt, was mit der hohen Geburt der Zöglinge begründet wird. ${ }^{18}$ Bedürfnisse adeliger Repräsentation dürften dabei mit den Interessen der Staatsadministration (sicherer Geschäftsstil, sicheres Auftreten) zur Deckung kommen. Dieser dominant lateinische Unterricht wird nun durch literarische Zusatzfächer ergänzt und differenziert. Wichtig ist der Deutschunterricht, der am Theresianum weder an den vorgelagerten Elementarunterricht abgegeben, noch auf den Einsatz der deutschen Sprache in Übersetzungsund Kommentierungsübungen reduziert wird. ${ }^{19}$ Hinzu kommen Studienmöglichkeiten bei Sprachmeistern in englischer, französischer, italienischer, tschechischer und ungarischer Sprache sowie bei Lehrpersonal für französische und für deutsche Rhetorik, für Ästhetik und für Schöne Literatur. ${ }^{20}$ Der literarische Unterricht entspricht mithin bereits in der Konzeption des Theresianums nicht einem konventionellen jesuitischen Studienprogramm, sondern war nach zeitgenössischen Forderungen von Stand und Staat ausgerichtet.

Zentraler Akteur in der weiteren Modernisierung des Unterrichts - nicht zuletzt als Reaktion auf staatliche Reformvorschriften zur Vereinheitlichung des österreichischen Schulwesens ${ }^{21}$ - war der im Jahr 1760 eingesetzte

17 „STatim atque Latinae Linguae Elementa jacta fuerint, optimorum Authorum praelectione, imitationeque assidua exercebuntur Adolescentes, ut sic non prompte modo, atque emendate latine eloqui, sed \& eleganter scribere, atque Authores quosvis interpretari, efferreque vernacula doceantur" (ebd., S. IV).

18 Vgl. Idea Collegii Regii Theresiani (Anm. 14), S. V; zum Zusammenspiel von Poesie und Rhetorik in Bezug auf die jesuitische eloquentia vgl. Barner, Barockrhetorik (Anm. 7), S. 339 .

19 „In Germanica praeterea Scriptura, Orthographia, Stylo [...] a primis annis erudientur" (Idea Collegii Regii Theresiani [Anm. 14], S. VII). Zum ambivalenten Status der Muttersprache in der Ratio studiorum vgl. Bernhard Duhr, Die Studienordnung der Gesellschaft Jesu, Freiburg/Br.: Herdersche Verlagsbuchhandlung 1896, S. 107-118.

20 Vgl. Gemmell-Flischbach (Hrsg.), Album des k. k. Theresianums (Anm. 13), S. 6-18.

21 Prominent der Instructio pro Scholis humanioribus von Giovanni Battista de Gaspari, die 1764 wirksam wurde. Vgl. Helmut Engelbrecht, Geschichte des österreichischen Bildungswesens. Erziehung und Unterricht auf dem Boden Österreichs, Bd. 3: Von der frühen Aufklärung bis zum Vormärz, Wien: ÖBV 1984, S. 149-151. 
Rektor Heinrich Johann von Kerens. Dieser bemühte sich gezielt um neues Lehrpersonal - für die Schönen Wissenschaften Michael Denis und Joseph Burkard - und erarbeitete einen neuen Lehrplan, der in seinen Grundzügen ab 1764 wirksam war. ${ }^{22}$ Mit diesen Reformen wurde auf den Paradigmenwechsel im Wissenschaftssystem des 18. Jahrhunderts und entsprechende Umstellungen in der Wissenschaftsorganisation reagiert; zugleich distanzierte man sich zunehmend von der Ratio studiorum als organisatorischer und didaktischer Norm. Primär wurde der juristische, staats-, natur- und hilfswissenschaftliche Fächerkanon erweitert und angepasst. ${ }^{23} \mathrm{Im}$ Bildungsbetrieb des 18. Jahrhunderts musste die Gesellschaft Jesu aber auch an literarischer Front agieren. Erstens war ein zeitgemäßer Umgang mit der kulturellen Anerkennung des Vernakulären und insbesondere des Französischen als Sprache internationaler Kommunikation zu finden; zweitens musste der Querelle und der ubiquitären Aufwertung neuerer Literatur Rechnung getragen werden. ${ }^{24}$ An weiteren internen Reformen des Theresianums ist insbesondere die Aufwertung des Französischen und Deutschen als Fächer und als Unterrichtssprachen sowie der dazugehörigen Rhetoriken und Literaturen zu nennen. Zudem wurden ,schöne Wissenschaften' und ,Bibliographie‘ als eigenständige Fächer eingeführt und das Griechische verstärkt unterrichtet. - Der Überblick zeigt einen nicht unbeträchtlichen Gestaltungsspielraum in der Selbstorganisation des Theresianums als Institution im Spannungsfeld konfligierender Ansprüche und konkreter Forderungen von jesuitischer, staatlicher und elterlich-adeliger Seite. Diese relative Autonomie bot günstige Rahmenbedingungen für einen kulturell innovativen Literaturunterricht in Wien.

22 Vgl. dazu und zum Folgenden im Detail Johann Schwarz, „Die niederen und höheren Studien an der k. k. Theresianischen Akademie in Wien. I. Theresianische Organisatio", in: Jahres-Bericht des Gymnasiums der k. k. Theresianischen Akademie in Wien (1903), S. 1-28; Johann Schwarz, „Die niederen und höheren Studien an der k. k. Theresianischen Akademie in Wien. II. Die Josefinische Studieneinrichtung“, in: Jahres-Bericht des Gymnasiums der k. k. Theresianischen Akademie in Wien (1904), S. 1-16.

23 Das Juridicum etwa an die Neuerungen vor allem im Bereich des Naturrechts; die Philosophie (insb. Physik) an die Experimentalphysik - letzteres entgegen der nach wie vor gültigen aristotelischen Ordensdoktrin. Vgl. Cerman, Habsburgischer Adel (Anm. 11), S. 222-241.

24 Vgl. John W. O'Malley, Une histoire des Jésuites. D'Ignace de Loyola à nos jours, Brüssel: Lessius 2014, S. 93. 


\section{Praxis}

Dahingehend ist nun nach den Gestaltungsmöglichkeiten durch Akteure innerhalb der Institution in der konkreten Lehrpraxis zu fragen. In der jüngeren Forschung zur Geschichte der Jesuiten wurde vermehrt das Verhältnis von Ordensdoktrin und Praxis problematisiert. O'Malley formuliert entsprechend ein praxeologisches Credo, wenn er dazu anhält, „à ne pas surestimer la valeur des textes normatifs lorsqu'il s'agit de comprendre les jésuites. Il faut les dépasser pour voir comment ils les ont mis en pratique - ou les ont ignorés ou bien dépassés. “25 Diese methodologische Kautel sei insbesondere in der Untersuchung des jesuitischen Bildungswesens zu berücksichtigen, das historisch von großzügigen Auslegungen oder gar Indifferenz gegenüber der Ratio studiorum gekennzeichnet gewesen sei. ${ }^{26}$ Die praxeologische Perspektive dient als Korrektur für eine Geschichtsschreibung, die an der Ordensdoktrin orientiert war; und das nicht als Geschichte dieser Doktrin, sondern mit dem Anspruch realgeschichtlicher Faktendarstellung, die aus normativen Dokumenten mehr oder weniger umstandslos deduziert wurde. ${ }^{27}$ Dieses forschungsgeschichtliche Problem hat indessen auch überlieferungsgeschichtliche Gründe. Die diskontinuierliche Geschichte der Gesellschaft Jesu ist nicht zuletzt eine Geschichte der Streuung, wo nicht der Vernichtung ihrer institutionellen Dokumentation. Dennoch liegen die Dinge für eine praxeologische Perspektive auf den literarischen Unterricht am Theresianum günstig. ${ }^{28}$

Für eine Geschichte der Praktiken aufschlussreich sind Denis' Schilderungen seiner Unterrichtstätigkeit:

1761. begann ich die Redekunst zu lehren, täglich durch 3 1⁄2 Stunde. Dazu kamen wöchentliche 2 Wiederholungsstunden, zwo jährliche öffentliche Prüfungen im Januar und September; vor der ersten gab ich durch 14 Tage, vor der zweyten

25 Ebd., S. 32.

26 Vgl. ebd., S. 53.

27 Ebenso ist eine praxeologische Korrektur gegenüber der „staatsfreundlichen Historiographie" zu behaupten. Zur Kritik dieser Tradition mit Blick auf die Institutionen adeliger Ausbildung im Wien des 18. Jahrhunderts vgl. Cerman, Habsburgischer Adel (Anm. 11), S. $222 \mathrm{f}$.

28 Das verdankt sich den autobiographischen Aufzeichnungen von Denis. Zwar bricht seine großangelegte Lebenserzählung Commentarii de vita sua mit dem Jahr 1759 ab; doch sind kleinere Berichte erhalten, die im Folgenden herangezogen werden. Michael Denis, „Michaelis Denisii Commentariorum de vita sua libri V“, in: Joseph Friedrich von Retzer (Hrsg.), Michael's Denis Literarischer Nachlass. Erste Abtheilung, Wien: Pichler 1801, S. $1-55$. 
durch einen Monat täglich eine ausserordentliche Stunde Wiederholung. Vor jeder Prüfung liess ich die Zuhörer durch einen Schüler lateinisch oder deutsch, gebunden oder ungebunden haranguiren. Die Gegenstände der Prüfungen waren: Rhetorik, Poetik, Erklärung der Classiker, Geschicht, Geographie, griechische Sprache, Rechenkunst und Religion. An Sonn- und Feyer- und Donnerstagen brachte ich Abendstunden meist in den Zimmern meiner Schüler zu, um bald diesen, bald jenen in Verfertigung ihrer schriftlichen Aufsätze zu leiten, und so habe ichs durch 13 Jahre unermüdet gehalten. ${ }^{29}$

Unermüdlich doziert Denis und begleitet die Schreibarbeit der Zöglinge. Zudem erarbeitet er Unterrichtsmaterialien in lateinischer und deutscher Sprache. Schon sein Lehrgedicht über die Beredsamkeit hatte seine Funktionsbestimmung im Schulgebrauch. Während seiner Lehrjahre am Theresianum entsteht eine kommentierte Anthologie von Gedichten deutscher Gegenwartsautoren „für die Jugend“; er elaboriert „für meine Classe eine kurzgefasste Gedankenlehre in Latein“ sowie „für meine Schüler einen lat[einischen] Lehrbegriff von allen Gattungen der Poesie, um ihnen die besten Dichter aller Nationen bekannt zu machen“; er verfasst wiederum „für meine Classe eine deutsche Geschicht der Beredsamkeit bey allen Völkern nebst einem Verzeichnisse aller vorzüglichen rhetorischen Werke“, bereitet die Bibliothek des Hauses für Studienzwecke auf und initiiert ein „Studium der Bibliographie und Literargeschicht" mit entsprechenden Lehrwerken. ${ }^{30}$ Diese Unterrichtsmaterialien sind von Denis für seine individuelle Lehrpraxis maßgeschneidert und entsprechen nicht den vom Theresianum für die Studien- und Lehrprogramme vorgeschriebenen Lehrbüchern. ${ }^{31}$ Ab 1763 beginnt Denis, der

29 Michael Denis, „Meine 25jährigen Beschäftigungen im Theresianum“, in: Retzer (Hrsg.), Michael's Denis Literarischer Nachlass (Anm. 28), S. 57-61, hier S. 57.

30 Ebd., S. 58-6o. Besonders erfolgreich war die Sammlung kürzerer Gedichte aus den neuern Dichtern Deutschlandes, zum Gebrauche der Jugend, 3 Bde., Wien: Kurzböck 1762ff. Bei Joseph Wolff in Augsburg erlebt die Sammlung Nachdrucke und Fortsetzungen. Joseph von Sonnenfels würdigt im Mann ohne Vorurtheil diese Publikation und schreibt ihr zu, deutsche Literatur in Wien allererst bekannt gemacht zu haben: „Noch ein Jahr vorher hätte ich erklären müssen: wer ist Kleist und Klopstock?“ (zit. n. Duhr, Die Studienordnung [Anm. 19], S. 12f.) Für den Unterricht in Bibliographie und Literaturgeschichte liegen als von Denis besorgte Lehrbücher im Druck vor: Grundriß der Bibliographie oder Bücherkunde, nach welchem an der k. k. theres. Ritterschule, auf Anleitung des Aufsehers der k. garellischen Bibliothek und Lehrers der Bibliographie und Literargeschichte Mich. Denis, die Herren, Christian Graf Aichholt [...] Den [] des Monats Augusts 1775. öffentlich geprüfet werden, Wien: Trattner o.J.; Einleitung in die Bücherkunde. Erster Theil. Bibliographie, Wien: Trattner 1777; Zweyter Theil. Literargeschicht, Wien: Trattner 1778.

31 Vgl. die bei Schwarz, „Die niederen und höheren Studien. I“ (Anm. 22), eruierten und in Fußnoten zugeordneten Titel. 
gängigen sozio-medialen Praxis von Gelegenheitsdichtung folgend, ${ }^{32}$ „einige Jünglinge in Ausgabe verschiedener Kleinigkeiten zu leiten“. ${ }^{33}$ Zudem dirigiert und kontrolliert er beinahe die gesamte repräsentative Textproduktion und -kommunikation der Schule oder erledigt sie gleich selbst:

In diesen 25 Jahren habe ich alle deutschen, an den Hof bey allen Feyerlichkeiten im Namen der Akademie gehaltenen Anreden verfasset, und die Redner im Vortrage unterrichtet, fast alle akademischen Anzeigen für die Zeitungen, und die meisten Bittschriften der Jünglinge an die Monarchen gemacht; so haben mich auch manche meiner Collegen vor Bekanntmachung ihrer Arbeiten um freundschaftliche Durchsicht derselben angesprochen, die ich niemals versaget habe. ${ }^{34}$

Selbst mit den nötigen Abstrichen hinsichtlich autobiographischer Inszenierung zeugen die Tätigkeiten vom Veränderungswillen des jesuitischen Literators. Er bereitet die Grundlagen für einen Unterricht, der als Ziel die literarische Kompetenz der adeligen Zöglinge auf Augenhöhe mit den literarischen Kulturen Westeuropas vorsieht. Wer ab den 176oer Jahren am Wiener Theresianum Literaturunterricht erhält, erlernt rezeptive, reflexive und produktive literarische Kompetenzen in mehreren Sprachen und in Auseinandersetzung nicht nur mit antiken Mustern, sondern auch mit der zeitgenössischen literarischen Produktion des deutschen Sprachraums und anderer europäischer Literaturen, studiert Literaturgeschichte, übersetzt und kommentiert Klassiker. Denis bezieht eine betont reformerische Position gegenüber der pädagogischen Tradition jesuitischer Latinität und der literarischen Tradition der Latinitas Austriaca. ${ }^{35}$ Damit reagiert er auf die im süddeutsch-österreichischen Raum zunehmend lauter werdende antijesuitische Sprachkritik und entspricht zugleich der politisch dringlichen Forderung nach der Durchsetzung des Deutschen als Sprache der

32 Vgl. Wulf Segebrecht, Das Gelegenheitsgedicht. Ein Beitrag zur Geschichte und Poetik der deutschen Lyrik, Stuttgart: Metzler 1977, S. 174-200.

33 Denis, „Meine 25jährigen Beschäftigungen“ (Anm. 29), S. 58.

34 Ebd., S. 61.

35 Im Medium der Latinitas Austriaca konnten Autoren strukturell-schlüssig den habsburgischen Katholizismus mit der Legitimierung des Kaiserhauses über die auf Rom bezogene translatio imperii integrieren. Vgl. zu diesem Modell Werner M. Bauer, „Latinitas Austriaca. Zur neulateinischen Dichtung der josephinischen Epoche“, in: Jahrbuch für Internationale Germanistik 30 (1998), H. 2, S. 32-115; Franz M. Eybl, „Probleme einer österreichischen Literaturgeschichte des 18. Jahrhunderts“, in: Wendelin Schmidt-Dengler et al. (Hrsg.), Literaturgeschichte: Österreich. Prolegomena und Fallstudien, Berlin: Schmidt 1995, S. 146-157, hier S. 152-154. 
Staatsadministration. ${ }^{36}$ Denis verfolgt mit seiner Unterrichtspraxis in der maria-theresianischen Ära an einer Institution des lateinischen Bildungswesens das Projekt eines literarischen Propädeutikums, mit dem er an der Ausbildung einer deutschsprachigen literarischen Kultur in Österreich mitarbeitet und das er öffentlichkeitswirksam ausrichtet. ${ }^{37}$ Eine institutionelle Innovation, die auf Denis' Betreiben zurückgeführt werden kann, ist diesbezüglich besonders bemerkenswert: „1763. fieng ich an, meine Schüler im Junius die jährlich von ihnen verfasste Aufsätze öffentlich ablesen zu lassen. Jedes Jahr wurde das Verzeichnis gedruckt ausgetheilet."38 Alljährlich kommt es zur feierlichen akademischen Vorlesung der Schülerarbeiten vor Publikum. Fixpunkt dieses repräsentativen Events ist die Überreichung der kalligraphisch elaborierten Texte an den Rektor, der sie in Sammlungen ablegen lässt (vgl. I, Vorbericht, unpag.). Diese literarische Leistungsparade der Schüler ist offensiv nach außen gerichtet. Zwar ist das Ausstellen von Schülerleistungen seit jeher gängige Praxis im jesuitischen Schulbetrieb, doch wird für das Theresianum im 18. Jahrhundert anzunehmen sein, dass es sich auch um eine Reaktion auf das zentrale strategische Argument gegen die erzieherische Dominanz des Ordens in der Hauptstadt handelt, wonach das Theresianum im großen Stil Zöglinge als Kleriker anwerbe und eine ungenügende säkulare Ausbildung anbiete. ${ }^{39}$ Anfang der 1770er Jahre entscheidet man sich schließlich im Rahmen dieser

$36 \quad$ Nach eigener Angabe ist es ihm mit seiner literaturpädagogischen und publizistischen Praxis darum zu tun, „den ungegründeten Vorwurf abzulehnen, welchen verschiedene Stutzer gewissen Gemeinden machen, als würde in selben allein die lateinische, und nicht auch die Muttersprache getrieben“ (Michael Denis, Poetische Bilder der meisten kriegerischen Vorgänge in Europa seit dem Jahre 1756, 2. Aufl., Wien: Kurzböck 176o, unpag. Vorbericht).

37 In der Literaturgeschichtsschreibung ist für das 18. Jahrhundert notorisch von einer ,doppelten Verspätung` österreichischer Literatur die Rede; einmal in Bezug auf die ,deutsche‘ Literatur und dann insgesamt in Bezug auf westeuropäische Literaturen. Vgl. zu diesem Periodisierungs- und Differenzierungsproblem österreichischer Literatur Werner Michler, „Austrian Literature of the 18th Century“, in: Thomas Wallnig, Johannes Frimmel und Werner Telesko (Hrsg.), 18th Century Studies in Austria, 1945-2010, Bochum: Winkler 2011, S. 187-206, hier S. 194-196.

38 Denis, „Meine 25jährigen Beschäftigungen“ (Anm. 29), S. 58.

39 Die einschlägigen Argumente gegen „die Erziehung durch Ordensgeistliche“ und insbesondere gegen die Wiener Jesuiten versammelt polemisch-gedrängt Nicolai, Beschreibung einer Reise (Anm. 3), S. 770-786. Als Beleg führt er das Wiener Hörensagen an. Zugleich moniert Nicolai die Praxis öffentlicher Zurschaustellung von Schülerleistungen: „Mit den Prüfungen wird übrigens im Theresianum eben solch ein Spielwerk getrieben, als in andern Anstalten, und in den Wiener Zeitungen ein eben so unnöthiges Aufheben davon gemacht" (ebd., S. 772f.). 
Repräsentationsarbeit für einen Medienwechsel - die Jugendfrüchte des $k . k$. Theresianum gelangen in den Druck.

\section{4. $\quad$ Gattung}

1772 und 1774 erscheinen drei Bände mit literarischen Texten von Zöglingen des Wiener Theresianums. Diese Zusammenstellungen von Proben schulischer Textarbeit in Prosa und in Versen sind historisch keine abseitige publizistische Unternehmung. Eine der renommiertesten Bildungseinrichtungen der Hauptstadt interveniert damit in einer Umbruchsphase der literarischen Kultur auf dem regionalen Buchmarkt. ${ }^{40}$ Die drei Bände im handlichen OktavFormat, gefällig gestaltet mit ornamentalen und topischen Vignetten, werden prominent hergestellt und vertrieben durch Joseph Kurzböck, k. k. illyrischund orientalischer Hofbuchdrucker. Sie finden in Wien begeisterte Aufnahme, werden aber auch überregional zur Kenntnis genommen, angezeigt und besprochen. ${ }^{41}$

Das Reich der Beredsamkeit in einem Traume eröffnet als erstes Stück die erste Sammlung derJugendfrüchte und ist dort kaum anders als programmatisch zu verstehen. Die darin propagierte und zugleich umgesetzte Übung anhand von Beispielen formiert den Produktionsprozess zahlreicher enthaltener Texte. Das motivisch-inhaltlich affirmierte Programm eines literaturdidaktischen Ciceronianismus ${ }^{42}$ wird hingegen relativiert. Franz Xaver Graf von Auerspergs Paraphrase folgt nämlich gerade nicht dem von der rhetorischen und pädagogischen Tradition legitimierten produktionsästhetischen Prinzip der

40 Vgl. Norbert Bachleitner, Franz M. Eybl und Ernst Fischer, Geschichte des Buchhandels in Österreich, Wiesbaden: Harrassowitz 2000, S. 103-157, zu den Jugendfrüchten S. 15of.

41 Für Österreich vgl. (nicht vollständig) Hofmann-Wellenhof, Michael Denis (Anm. 9), S. 350. Darüber hinaus fördert bereits eine kursorische Suche diverse Rezensionen zu Tage. Aufgeführt seien: Gothaische gelehrte Zeitungen, 13. Stück, 15.02.1775, S. 98f.; Historisches Journal, von Mitgliedern des königlichen historischen Instituts zu Göttingen, Achter Theil, den litterarischen Beitrag enthaltend (1776), S. 124; Almanach der deutschen Musen auf das Jahr 1777 (Leipzig), S. 46f.; Allgemeine deutsche Bibliothek, Anh. 13.-24. Bd., 1. Abt. (1777), S. 439-441. Für die Bekanntheit der Jugendfrüchte spricht zudem die vergleichende Erwähnung in einer Rezension von Kleine Rednerische Aufsätze von Jünglingen für Jünglinge, Basel: Schweighauser 179o, in: Allgemeine Literatur-Zeitung (1791), Bd. 3, Nr. 25o, Sp. 572-574, hier Sp. 573 .

42 Vgl. Jörg Robert, „Die Ciceronianismus-Debatte“, in: Herbert Jaumann (Hrsg.), Diskurse der Gelehrtenkultur in der Frühen Neuzeit. Ein Handbuch, Berlin, New York: de Gruyter 2011, S. 1-54. 
imitatio veterum, das auf einen normativen Kanon von Klassikern bezogen wäre - die Vorlage ist nur rund 15 Jahre alt und ihr Autor kein Cicero und kein Horaz. Zudem übersetzt Auersperg das Denis'sche Latein ins Deutsche; auch das gehört zur Programmatik der Jugendfrüchte, die im Gegensatz zur polyglotten Unterrichtspraxis und den mehrsprachigen öffentlichen Vorlesungen ausschließlich Texte in deutscher Sprache enthalten..$^{43}$ In den vorgeschalteten Registern der Einzelbände geben die Titel Auskunft über Entstehungszeitpunkt, behandelte Gegenstände, anverwandelte literarische Vorlagen, gegebene Anlässe und Gattungszugehörigkeit der einzelnen Texte. Damit wird die Verortung der Schülertexte in zeitgenössischen literarischen Bezugssystemen vorgenommen. Die Palette der bedienten literarischen Formen und Gattungen bildet - mit Ausnahme dramatischer Dichtung - das Gros der generischen Möglichkeiten deutscher Literatur zur Jahrhundertmitte ab - von Huldigungsreden über satirische Briefe und Freundschaftsoden bis hin zu Versuchen in komischer Versepik. ${ }^{44}$ Wenige Genres sind nicht aufgenommen; einerseits aus vermutlich pragmatischen Gründen wie der Roman, andererseits aufgrund von wertungsbasierten Ausschlüssen. So ist gemutmaßt worden, dass beispielsweise Fabeln und moralische Erzählungen wegen des „Ethos dieser Gattung“ mit ihrer "plebejische[n]" Moraldidaxe der Adelserziehung nicht angemessen seien. ${ }^{45}$ Die barocke Formensprache von Sonett und Madrigal sowie die Rokokodichtung werden unterdessen auf der Basis stilistischer Wertungen ausgeschlossen. ${ }^{46}$ Derartige Kanonisierungsmanöver werden von mehreren Texten explizit durchgespielt. In Auerspergs Das Reich der Beredsamkeit in einem Traume findet sich beispielsweise eine Beschreibung des locus terribilis, an den jene verbannt werden, die sich nicht an attizistische Stilideale halten:

Wir erblickten eine angenehme, dicht mit Blumen besäete Gegend. Ich schrie alsobald auf: O glückselig! dem erlaubt ist dieses so anmuthigen Lenzes zu genießen! Wie wünschte ich nicht hier zu verbleiben! Mein Führer aber sprach lächelnd: Wünsche nicht so laut, o Jüngling! betrachte vorher die bleichen entstellten Angesichter der Einwohner, und riech den unmäßigen Blumenduft, der die Geister schwächt, und lerne wünschen. Diese flieh! fuhr er ernsthafter fort. Denn diese hatten sich zwar einst dem Dienste unsrer Göttinn gewidmet;

43 „Noch wäre nebst einigen französischen und italienischen ein eben so grosser Vorrath lateinischer Ausarbeitungen in den Händen der Herausgeber" (I, Vorbericht, unpag.).

44 Für eine systematische Autopsie der Bände im Detail vgl. Wolfgang Martens, „Drei Sammlungen von Schülerdichtungen aus dem Wiener Theresianum“, in: Zeman (Hrsg.), Die österreichische Literatur (Anm. 5), S. 1-22, hier v.a. S. 6 f.

45 Ebd., S. 16.

46 Vgl. ebd., S. 7 und S. $12 f$. 
allein in kurzer Zeit erdachten sie sich eine neue Beredsamkeit, die nicht in männlichem Anstande majestätisch einhertrat, sondern wie eine geschmückte Tänzerinn weichlich herumflatterte. Sie füllten alles mit Gold, Silber, Diamanten, Helfenbein, Krystall, Hyacinthen, und Narcissen an. Allenthalben blinkten falscher Witz, und Wortspiele. (I, S. 11)

Der Tendenz nach vergleichbare Beiträge in poetologischer Lyrik führen die antibarocke literaturästhetische Wertungskompetenz der Theresianisten vor. ${ }^{47}$ Daneben ist eine Hinwendung zu Kasualpoesie im Dienst der Monarchie feststellbar, ein gegenständlicher Fokus auf Fragen adeliger Lebensführung sowie ein zeitgeistiger Vorzug für reimlose Versdichtung nach Klopstock, Michael Denis und der Bardenmode; die zeitgenössisch brisante Dichtung des Sturm und Drang findet hingegen keinerlei Berücksichtigung. Diese zusammenfassende Sichtung der Jugendfrüchte lässt neben funktionalen Erklärungen - Adelserziehung, Dienst am Herrscherhaus, Einübung patriotischer Verantwortlichkeiten - eine Bestimmung des Referenzkanons $\mathrm{zu}$, dem die musterhaften Beispiele für die nachahmenden Schülerarbeiten entstammen:

Es ist die Formenwelt der um die Jahrhundertmitte führenden deutschen Schriftsteller Ober- und Niedersachsens und der deutschen Schweiz. Von Hagedorn über die Bremer Beiträger mit Gellert, Rabener, Zachariae, Cramer und Klopstock bis zu Haller, Geßner und dem jungen Wieland im Bannkreis Zürichs zieht sich die Reihe der Vorbilder. ${ }^{48}$

Derälteren Forschung haben dieJugendfrüchte keine nennenswerten Schwierigkeiten bereitet. Sie wurden als schul- und literaturgeschichtliches Kuriosum der maria-theresianischen Ära verzeichnet. Jene zwei Studien, die sich der Sache eingehender widmen, nehmen hingegen eine deutliche Beurteilung vor. Paul von Hofmann-Wellenhof disqualifiziert das Unternehmen als epigonal. Mit begrifflichen Maßstäben des Paradigmas individueller Kreativität

47 Ein Beispiel, wiederum in Abwertung des Barock-Asianismus, aus Anton Graf von Apponyis Germanien frohlocket über den Wachsthum ihrer Dichtkunst (II, S. 133-142): „Nur falsches Irrlicht schien in einem Lohenstein, / Er war voll eitles Schwulsts, und wollt' erhaben seyn. / Von gleichem Flittergold wollt' Hofmannswaldau glänzen, / Unächter Schönheit voll entschwang er sich den Gränzen, / Die der gesunde Witz und der Geschmack uns setzt, / Die noch kein Busenfreund des Dichtergotts verletzt“ (II, S. 135).

48 Martens, „Drei Sammlungen“ (Anm. 44), S. 7f., hat herausgestellt, wie maßgeblich diese Auswahl von Denis' "Schulanthologie“ Sammlung kürzerer Gedichte aus den neuern Dichtern Deutschlandes für die Jugend geprägt ist und den von Johann Thomas Trattner auf dem Wiener Buchmarkt platzierten Nachdrucken deutscher Schriftsteller entspricht (ebd., S. 7 f.). 
ausgerüstet, erledigt er die Sache mit der Behauptung einer Denis'schen Manier rundweg aller gesammelten Texte, die sich als „schülerhafte Nachahmungen“ dem Stil des Lehrers anbiedern. Einzig Michael Denis selbst sei als Autor originell und somit von Interesse. ${ }^{49}$ Und auch Wolfgang Martens, der auf Basis umfassender Textanalysen die facettenreiche Orientierung der Jugendfrüchte an zeitgenössischen Tendenzen der literarischen Aufklärung herausarbeitet, bemerkt - ansonsten mit Wertungen eher zurückhaltend -, dass „keine Stimme auszumachen [sei], die aus dem Chor der hier beteiligten 73 Verfasser originell hervorklänge“. ${ }^{50}$ Selbst in der Institutionsgeschichte zum Theresianum wird bis heute mit Geschmacksurteilen, die sich unhinterfragten Voraussetzungen idealistischer Ästhetik verdanken, nicht hinter dem Berg gehalten. ${ }^{51}$ Literatur als ästhetische und soziale Praxis im Kontext kann dadurch gar nicht erst in den Blick rücken. Dem Vorwurf der Epigonalität wäre jedenfalls historisch entgegenzuhalten, dass die imitatio um 1770 noch der literarische Normalfall ist: „Eigene und fremde Lesefrüchte zirkulieren in einem Raum, in dem die Nachahmung öffentlich und achtbar ist. Dieser Raum, die gebildete Öffentlichkeit (res publica literaria), reicht bis zum Ende des 18. Jahrhunderts. So weit wie die lateinischen Bildungsanstalten selber. ${ }^{\text {“2 } 2}$ Die Situation des Literaturunterrichts am Theresianum steht am Übergang einer historischen Entwicklung, in der ,jene[r] homologe[] Textstrom (literatura), bei dem sich Bücher und Schularbeiten allenfalls qualitativ unterscheiden“, ${ }^{53}$ erst allmählich kulturell und sozialfunktional ausdifferenziert wird. Im Verlauf dieser Entwicklung vom literarischen Imitations- zum Originalitätsdispositiv wird Schule dann zu „einem Schon- und Übungsraum“, in dem Imitation eingehegt, aber mit einem

49 Hofmann-Wellenhof, Michael Denis (Anm. 9), S. 343-351.

50 Martens, „Drei Sammlungen“ (Anm. 44), S. 8. Deutlich positiver in der Wertung ist jüngst - en passant - Wynfrid Kriegleder, „Die deutschsprachige Literatur in Wien um 1740“, in: Elisabeth Fritz-Hilscher (Hrsg.), Im Dienste einer Staatsidee. Künste und Künstler am Wiener Hof um 1740, Wien u.a.: Böhlau 2013, S. 47-64, hier S. 58: „Sie [die Jugendfrüchte; T. A.] enthalten poetische Arbeiten der Schüler von bemerkenswerter Qualität. Die Texte sind ästhetisch auf der Höhe der Zeit“.

$5^{1}$ In der maßgeblichen Geschichte des Hauses meint Guglia, die Jugendfrüchte „wären nun freilich besser nicht gedruckt worden“ (Eugen Guglia, Das Theresianum in Wien. Vergangenheit und Gegenwart, Wien: Schroll 1912, S. 86f.). Noch in der erweiterten Neuauflage von 2015 ist nachzulesen, dass die Jugendfrüchte „[b]ereits damals eigentlich eine Peinlichkeit“ gewesen seien (Guglia et al., Die Theresianische Akademie [Anm. 11], S. 82). Heinrich Bosse, „Die Schüler müßen selbst schreiben lernen` oder: Die Einrichtung der Schiefertafel“, in: ders., Bildungsrevolution 1770-1830, hrsg. von Nacim Ghanbari, Heidelberg: Winter 2012, S. 161-192, hier S. 163.

Ebd., S. 162. 
Gebot der Nichtveröffentlichung belegt werden wird. ${ }^{54}$ Das ist allerdings für die Wiener Situation um 1770 keineswegs zu postulieren.

Stattdessen soll nun skizzenhaft eine andere Fassung des Zusammenhangs von neuerem Referenzkanon und Jugendfrüchten in der literarischen Praxis am Theresianum als jene der wertungsintensiven Autoren-Epigonalität vorgeschlagen werden: die einer literaturdidaktischen und kulturübersetzenden Transferleistung, die gattungsförmig strukturiert ist. Bilden, so ist zu fragen, die Jugendfrüchte nicht eine spezifische bildungsinstitutionelle Gattung und fungieren so als Vehikel literarischer Didaxe? Man könnte versuchen, die Jugendfrüchte mit dem der (Editions-)Philologie entlehnten Terminus der Juvenilia auf den Begriff zu bringen, der in der zweiten Hälfte des 18. Jahrhunderts an Kontur gewann. Als philologische Kategorie bezeichnen Juvenilia jene literarischen Arbeiten eines Schriftstellers, die nicht eigentlich zu seinem Werk gehören; es sind Texte aus der Schaffensperiode, noch bevor er zum werkfähigen Autor geworden ist. ${ }^{55}$ Dieses schaffensbiographische Modell fügt sich recht gut in die Vorstellung, wonach literarische Übungen im geschützten Raum der Schule und somit im Dispositiv der imitatio als Vorbereitung für genuine Literaturproduktion im Ernstfall dienen. In der Konstellation am Theresianum um 1770 ist die Lage ungleich interessanter, weil mit den Jugendfrüchten literarische Modelle und Gattungen - primär aus den protestantischen Kulturräumen - im österreichischen Kontext allererst adaptiert und als poetische Optionen einer jungen Generation von möglichen Schriftstellern profiliert werden. Juvenilia wären in diesem Fall eine Gattung zweiter Ordnung, die in selektiver generischer Repräsentativität auf Konventionen anderer - genuin literarischer - Gattungen bezogen ist. Diese primären Gattungen werden in Juvenilia exemplarisch realisiert und zugleich in didaktischer Absicht vorgeführt. Als Merkmale sind zudem die relative Kürze der Einzeltexte anzugeben, die stets kollektive Präsentation mehrerer Texte in Druck oder mündlichem Vortrag sowie die jugendliche Autorschaft.

\footnotetext{
54 Ebd., S. 164.

55 Theoretische Voraussetzung für diesen Begriff ist die „Verzeitlichung des Werks zum Lebenswerk“ und die „Integration des Frühwerks“ in diesen Zusammenhang (Steffen Martus, Werkpolitik. Zur Literaturgeschichte kritischer Kommunikation vom 17. bis ins 20. Jahrhundert mit Studien zu Klopstock, Tieck, Goethe und George, Berlin, New York: de Gruyter 2008, S. 196). „Die Eingliederung der Juvenilia in das Interessenfeld und damit die Konstitution eines Lebenswerks ist eine Neuerung, $[\ldots]$ die sich allmählich in der zweiten Hälfte des 18. Jahrhunderts [...] etabliert" (ebd., S. 361).
} 


\section{Kollektiv}

An der paratextuellen Präsentation in der Titelei des ersten Bandes der Jugendfrüchte fällt auf, dass es keine namentlichen Autoren- oder Herausgebernennungen gibt. Die Jugendfrüchte erscheinen als vom Theresianum verantwortetes Publikationsunternehmen literarischer Texte aus der Schule: „Die Verfasser davon sind adeliche Jünglinge zwischen 14 und 17 Jahren; denn in diese Zeit fällt auf der theresianischen Ritterschule der besondere Unterricht in der schönen Literatur, der durch zwey Jahre fortgesetzet wird.“ (I, Vorbericht, unpag.) Erst als Unterzeichnete der einzelnen Texte werden die schreibenden Zöglinge individualisiert. ${ }^{56}$ Sie bekommen ihre Autorenposition in einem institutionell sanktionierten Produktionskollektiv zugewiesen und werden als Einzelne unter Gleichen zwischen zwei Buchdeckeln versammelt. In der zweiten und dritten Sammlung wird dieses Präsentationsmodell beibehalten, doch die Verfassernamen werden stärker hervorgehoben, indem sie bereits im „Verzeichnis der vorkommenden Stücke“ angeführt werden. Diesem paratextuell formierten schulischen Kollektiv entspricht die vorgestellte Einrichtung der Schreibarbeit: „Sie [i. e. die Schüler] arbeiten unter Anleitung und Kritik ihrer Lehrer, immer in genauem Verhältnisse mit ihren Fähigkeiten.“ (I, Vorbericht, unpag.) Konsequent werden mit der zünftigen Pluralbildung „Lehrlingsstücke“ (I, Vorbericht, unpag.) schließlich auch die Texte selbst in den ausbildungsinstitutionellen Rahmen gesetzt. Im Publikationsprojekt der Jugendfrüchte wird die jeweils nur schwach ausgeprägte individuelle Autorfunktion neu konfiguriert und in die Autorschaft eines elitären jugendlichen Produktionskollektivs überführt.

Der Vorbericht zum ersten Band gibt das intendierte literarische Kommunikations-, oder genauer, Wirkungsszenario der Jugendfrüchte vor:

Diese Sammlungen sind der vaterländischen Jugend gewidmet. Da es ihr an Mustern nicht fehlt, nach welchen sie sich bilden kann, so will man sie mit Beyspielen ermuntern, die von ihrem Alter genommen, und eben dadurch kräftiger sind ihre Liebe zu den schönen Wissenschaften und Nacheiferung zu erwecken. (I, Vorbericht, unpag.)

56 Das wird in der zeitgenössischen Rezeption hervorgehoben und ins pädagogische Verhältnis gesetzt: „Am Ende eines jeden Aufsatzes stehet der Name des Verfassers, und diese kleine Ehre, die der Eigenliebe junger Leute so sehr schmeichelt, ist in der That mehr, als alle andere Schulprämien, geschickt, sie zur Nacheiferung anzuspornen“ (Rez. in: Allgemeine deutsche Bibliothek, Anh. 13., 24. Bd., 1. Abt. (1777), S. 440). 
An die Definition des Adressaten wird die Funktionsbestimmung der Texte als exempla gekoppelt, die ganz besonders geeignet seien, zum nachahmenden Wetteifer der aemulatio anzuspornen. Mit dieser Qualifizierung der Jugendfrüchte wird eine produktionsästhetische Konkurrenzsituation entworfen: Die „vaterländische[] Jugend“ insgesamt ist angehalten, den Vorbildern aus den Jugendfrüchten gleichzukommen oder sie zu übertreffen. Dabei kommt es zu einer weiteren Umgestaltung des Bezugskanons vorbildlicher auctoritas. Sind die Muster für die dichtenden Zöglinge schon nicht mehr allein die antiken Größen der imitatio veterum, sondern entstammen zu einem großen Teil der für den Unterricht ausgewählten deutschsprachigen Gegenwartsliteratur, werden die Ergebnisse dieser Schulübungen nun selbst zu Mustern stilisiert. Ein exemplarischer Kanon wird am Theresianum also nicht nur in Auswahl und Zusammenstellung von Denis neu organisiert, sondern in Form von Juvenilia gleich selber geschrieben und öffentlich vorgelegt. Seine Reichweite wird mit der intendierten Geltung für die „vaterländische[] Jugend“ begrenzt. ${ }^{57}$ Mit dieser konzeptuellen wie habituellen Herauslösung aus regional nach wie vor dominanten (antiken) Traditionsbezügen geht eine relativ eigenständige Positionierung der Jugendfrüchte als österreichische Literatur in deutscher Sprache einher. Mit den neuen Gattungsoptionen deutschsprachiger Literatur wird eine ganze Generation potenzieller Dichter versorgt.

Diese publizistische Inszenierung wird von den Jugendfrüchten historischideologischabgesichert.Das MottoaufdenTitelblätternallerdreiBände-Juvenis Juvenem appello, quo minor sit inter nos hujus Sermonis verecundia. - korreliert das Szenario literarischer Konkurrenz mit einer Episode aus der römischen Kriegsgeschichte. Zum Ende des 26. Buchs von Ab urbe condita schildert Livius die erste kriegerische Unternehmung des Scipio in Spanien: die Eroberung Neu-Carthagos. Von dort aus soll der weitere Feldzug gegen die punischen Heere auf der iberischen Halbinsel orchestriert werden. Nach der erfolgreichen Einnahme der Stadt macht sich der Feldherr umgehend an die Neuaufstellung seiner Streitkräfte und an die Reorganisation des städtischen Lebens. In den Bericht vom Konsolidierungsprozess der Besatzungsherrschaft über Carthago Nova schaltet Livius eine Episode ein, die zu einem vielbearbeiteten Stoff in den Künsten und Literaturen des frühneuzeitlichen Europa avancieren wird.

57 „Dies ist der einzige Zweck der Herausgeber, die zu viel Achtung für das Publikum haben, als daß sie ihm Lehrlingsstücke in einer anderen Absicht vorlegen sollten“ (I, unpag. Vorrede). Diese Geltungseinschränkung von Texten gleichsam außer literarischer Konkurrenz ist identisch mit der Adressatenbestimmung einer ähnlichen Publikation: Kleine Rednerische Aufsätze (Anm. 41), S. III: „Hier sind - keine Reden für Meister und Gesellen - nur Anlagen zu Reden, nur rednerische Uebungen - von Jünglingen - für Jünglinge!“ 
Als Scipio von seinen Soldaten eine junge Gefangene von vollkommener Schönheit übergeben bekommt, lässt er umgehend nach ihrem Verlobten, dem keltiberischen Fürsten Allucius, schicken. Scipio händigt dem in die Stadt geeilten Allucius die namenlose Verlobte aus und verehrt ihm das von deren Eltern vorgestreckte Lösegeld als Hochzeitsgeschenk. Vertrauensvoll wendet sich der Feldherr an den Fürsten und beschwört die Bande der generationellen Gleichheit:

Iuvenis inquit iuvenem appello, quo minor sit inter nos huius sermonis verecundia. Ego cum sponsa tua capta a militibus nostris ad me ducta esset audiremque tibieam cordi esse, et forma faceret fidem, quia ipse, si frui liceret ludo aetatis, praesertim in recto et legitimo amore, et non res publica animum nostrum occupasset, veniam mihi dari sponsam impensius amanti vellem, tuo cuius possum amori faveo. Fuit sponsa tua apud me eadem, qua apud soceros tuos parentesque suos, verecundia; servata tibi est, ut inviolatum et dignum me teque dari tibi donum posset. Hanc mercedem unam pro eo munere paciscor: amicus populo Romano sis et, si me virum bonum credis esse, quales patrem patruumque meum iam ante hae gentes norant, scias multos nostri similes in civitate Romana esse nec ullum in terris hodie populum dici posse, quem minus tibi hostem tuisque esse velis aut amicum malis. ${ }^{58}$

Allucius bringt seine Verlobte zurück in keltiberisches Hoheitsgebiet und zeigt sich Scipio und Rom erkenntlich, indem er sich mit 1.400 frisch ausgehobenen Reitern dem Feldzug gegen die punischen Heere anschließt. Diese Episode von der clementia und continentia Scipios fungiert in der Frühen Neuzeit als ideologisch hoch aufgeladener Dauerbrenner für Herrschaftslegitimation und als Exempel militärisch-imperialer Klugheit. ${ }^{59}$

In der Aktualisierung dieser Episode für das Publikationsunternehmen einer Wiener Ritterakademie des 18. Jahrhunderts kommt es zur Überblendung einer translatio studii mit einer translatio imperii. Die Söhne des erbländischen Adels bringen eine neuartige Literatur nach Wien. Die herausfordernde Konkurrenzlogik in der ämulativen Adressierung wird als Kolonisierungsszenario ausgewiesen, in dem die Erziehungsanstalt mit römisch-imperialer Geste auftritt.

Akzeptiert man diese Deutung der Motti, wird die Inszenierung der Jugendfrüchte und der literarischen Praxis am Theresianum als spezifisch österreichische Variante von "representations of schooling as a kind of warfare“

$5^{8}$ Liv. XXVI, 50, 4-8, zit. n. Titus Livius, Ab urbe condita. Liber XXVI / Römische Geschichte. 26. Buch (Der Zweite Punische Krieg VI), Lateinisch/Deutsch, übersetzt und hrsg. von Ursula Blank-Sangmeister, Stuttgart: Reclam 2006, S. 182f.

59 Vgl. David Kunzle, From Criminal to Courtier. The Soldier in Netherlandish Art 1550-1672, Leiden, Boston: Brill 2002, S. 507-572. 
aufzufassen sein, die mit der institutionell hergestellten Erziehungssituation von Kompetitivität, Patriarchat und Homosozialität zusammenhängt, die Sarah Knight als typisch für das frühneuzeitliche Bildungswesen beschrieben hat. ${ }^{60}$ Das Produktionskollektiv des Theresianums wäre dementsprechend als Akteur im literarischen Leben agonal ausgerichtet. Als programmatisch ist hier erneut auf Auerspergs Das Reich der Beredsamkeit in einem Traume zu verweisen. Die dem träumenden Ich-Erzähler von Cicero und der Nymphe Nachahmung vorgestellten rhetorischen Kategorien werden in ihrer Funktion nämlich durchweg in Metaphern der Kriegskunst erläutert; die in Ausbildung stehenden Zöglinge lernen, auf dieses Arsenal von sprachlich-literarischen Mitteln als auf „Waffen“ zurückzugreifen. ${ }^{61}$

Das publizistische In-Stellung-Bringen der Schüler korrespondiert mit der institutionellen Formierung von Zöglingskollektiven im jesuitischen Schulbetrieb. Das erzieherische Modell der Jesuitenkollegia mit seinen romanisierenden Formierungsregeln und -praktiken wurde von Foucault als beispielgebend für Institutionen der Disziplinierung insgesamt erkannt. ${ }^{62}$ In Norm und Praxis des jesuitischen Unterrichts ist Rom, genauer: ein römisches „Kampf- und Kriegsspiel“63 zentraler Referenzpunkt und Organisationsform:

Nehmen wir das Beispiel der „Klasse“. In den Jesuitenkollegs gab es noch eine Organisation, die zugleich massiv und dualistisch war. Die Klassen, die bis zu 200 oder 300 Schülern [sic!] zählten, waren in Zehnergruppen geteilt. Jede dieser Gruppen hatte einen Dekurio und stand entweder im Lager der Römer oder in dem der Karthager, so daß jeder Dekurie eine feindliche gegenüberstand. Der Krieg und die Rivalitäten bildeten die allgemein herrschende Form. Die Arbeit, das Lernen, die Klassifizierung spielten sich im Zweikampf oder in der Auseinandersetzung zwischen den beiden Armeen ab. Die Leistung jedes Schülers zeichnete sich in diesem allgemeinen Duell ab, und sie trug ihrerseits zum Sieg oder zur Niederlage eines Lagers bei. Jedem Schüler wurde ein Platz zugewiesen, der seiner Rolle und seiner Tüchtigkeit als Mitkämpfer in der einheitlichen Gruppe der Dekurie entsprach. [...] Diese römische Komödie kombinierte übrigens die Rivalitätsübungen mit einer von der Legion inspirierten Raumordnung: mit Rang, Hierarchie, pyramidenförmiger Überwachung. ${ }^{64}$

6o Sarah Knight, „How the Young Man Should Study Latin Poetry. Neo-Latin Literature and Early Modern Education“, in: Victoria Moul (Hrsg.), A Guide to Neo-Latin Literature, Cambridge: Cambridge University Press 2017, S. 52-65, hier S. 55 .

61 „Wir wollen die Vorrathshäuser der Göttinn betrachten. Hieraus holt sich Suada die Waffen, mit welchen auch du, o Jüngling! wider Unrecht, Laster und Wahn einst wirst streiten müßen" (I, S. 15; vgl. auch I, S. 5 und passim).

62 Vgl. Michel Foucault, Überwachen und Strafen. Die Geburt des Gefängnisses, übersetzt von Walter Seitter, Frankfurt/Main: Suhrkamp 1977, S. 181-192.

63 Ebd., S. 188.

64 Ebd., S. 187. 
Die „Parzellierung“ (Foucault) der Zöglinge in Kameraten und ihre Aufteilung in Paare von aemuli, die in dauernder Konkurrenz zueinander stehen, sind als pädagogische Prinzipien von Ehrgeiz, Konkurrenz und Prämierung von der Ratio studiorum festgelegt. Gegenseitige Überbietung und Wetteifer zeichnen also schon die Unterrichtsabläufe selber aus. ${ }^{65}$ Gekoppelt ist das - und wohl noch vermehrt am Theresianum als Collegium nobilium - an ein ausgeprägtes Elitenbewusstsein der Schüler. ${ }^{66}$

Michael Denis fungierte als Herausgeber der ersten und dritten Sammlung der Jugendfrüchte. Den zweiten Band besorgte sein „College [Joseph] Burkard, der rühmlich in allem mit mir eiferte“. ${ }^{67}$ Selbst auf Ebene der Lehrer wird also von Konkurrenz berichtet; diese wird aber nicht, etwa durch Personalisierung der Herausgeberfunktion, öffentlich ausgetragen, sondern bleibt im Schulkollektiv aufgehoben. Als Herausgeber trafen Denis und Burkard die Auswahl für die Publikation aus jenen Schülertexten, die zur jährlichen Vorlesung präsentiert wurden, und nahmen zum Teil thematische Gruppierungen vor. Zusätzlich nahmen sie für andere Gelegenheiten verfasste und auch in Einzeldrucken bereits erschienene Schülertexte von besonderer Qualität in ihr Buchprojekt auf. Die Jugendfrüchte sind also von institutionellen Autoritäten zusammengestellt und zum Druck befördert worden. Die hierarchische Struktur und das souveräne editorische Agieren der Lehrer - in Auswahl, Anpassung und Bewertung der Texte - sind wesentliche Aspekte dieser ,kollektiven' Publikation, die in der öffentlichen Darstellung kaschiert wurden, wie auch die agonale Praxis unter den Zöglingen selbst nicht zur Geltung gebracht wurde.

Das Kollektiv literarischer Praxis am Theresianum wurde mithin, erstens, institutionell-direktiv formiert, durch Zugangsregulierungen (Adel, Schulgeld, Konfession), durch die Regulierung von Art und Inhalt des Unterrichts, von Schreibdiätetik und alltäglichem Zusammenleben (Zehner-Gruppen, kein unbeobachteter Kontakt untereinander). Dann konstituiert sich, zweitens,

65 Foucaults Beurteilung als soziale Zurichtungsapparate stehen betont positive Beschreibungen dieser pädagogischen Prinzipien von Ehrgeiz und Wettstreit gegenüber. Vgl. jüngst Martin Korenjak, Geschichte der neulateinischen Literatur. Vom Humanismus bis zur Gegenwart, München: Beck 2016, S. 127f. Für Entsprechungen in der Ratio studiorum und bereits historisch divergente Einschätzungen dieser Praxis der honesta aemulatio oder auch sancta aemulatio vgl. Duhr, Die Studienordnung (Anm. 19), S. 58-64.

66 Dieses ist typisch für das lateinische Bildungswesen im neuzeitlichen Europa mit allein schon immenser sprachlicher Distinktion. Vgl. dazu Françoise Waquet, Le latin ou l'empire d'un signe. $X V I^{e}-X X^{e}$ siècle, Paris: Albin Michel 1998, S. 252-258. 
dieses Kollektiv aber auch mittels konkreter Praktiken: der theoretischen Unterweisung, des Lesens, Schreibens, Paraphrasierens, Korrigierens, Vortragens, Beurteilens, Archivierens, Selegierens und Veröffentlichens. Diese routinisierten Handlungen werden teils vom Lehrpersonal, teils von den Zöglingen, oder auch von beiden ausgeübt. Dabei entsteht ein komplexes Gefüge, das sowohl horizontal zwischen den Zöglingen als auch vertikal (instruierend, korrigierend, beurteilend) strukturiert ist.

Unter Zeitgenossen hat die literarische Qualität mancher Jugendfrüchte für große Verwunderung gesorgt. Das ist - positiv - in einem Brief Christian Felix Weißes nachzulesen. ${ }^{68}$ Es haben sich aber auch Böswillige und Neider nicht bitten lassen: So musste sich Denis gegen die üble Nachrede verwahren, er habe die gesamten Jugendfrüchte selbst geschrieben: „Ungünstige, und Jünglinge, die ihr Unvermögen, etwas Ähnliches zu leisten, fühlten, liessen sich in späteren Jahren beygehen, alles dieses geradeweg für Professorarbeiten zu erklären." ${ }^{“ 9}$ Hier kam es zu einer aufschlussreichen Ersetzung: Die Produkte einer sowohl in der Inszenierung als auch in der Umsetzung, wenn auch stark hierarchisierten, so doch kollektiven Praxis wurden bereits zeitgenössisch unter dem Aspekt originaler und also individueller Autorschaft problematisiert und vom Sammelwerk in ein Autorenwerk umgedeutet. Wo sich "Autorschaft" als „Werkherrschaft" konstituiert, ${ }^{70}$ scheint der Status kollektiver Praxis und entsprechender Publikationsformen prekär.

\section{Ausblick}

Inwiefern die literarische Praxis am Theresianum als Faktor für die historische Entwicklung der deutschsprachigen literarischen Kultur in Österreich einzukalkulieren ist, bliebe zu fragen. Die zeitgenössischeWahrnehmung von Michael Denis als „Vater und Lehrer" der „Oesterreichische[n] Dichterschule“ lässt es

68 Weiße an Denis. 20.10.1771, in: Joseph Friedrich von Retzer (Hrsg.), Michael's Denis literarischer Nachlass. Zweyte Abtheilung, Wien: Pichler 1802, S. 146f. Weiße lobt darin die Ausarbeitung eines „Trauergesanges auf unsern guten Rabner“ von einem 15-jährigen „edlen Jünglinge“, die später in die Jugendfrüchte aufgenommen werden wird (Johann Graf Hadik, Trauergesang auf Rabeners Tod, in: I, S. 357-364).

69 Denis, „Meine 25jährigen Beschäftigungen“ (Anm. 29), S. 59f.

70 Vgl. Heinrich Bosse, Autorschaft ist Werkherrschaft. Über die Entstehung des Urheberrechts aus dem Geist der Goethezeit, neue, mit einem Nachwort von Wulf D. von Lucius versehene Auflage, Paderborn: Fink 2014. 
ratsam erscheinen, ${ }^{71}$ dieses literarische Propädeutikum und seine kulturelle Wirkung nicht zu marginalisieren. Nicolai vermerkt dazu: „Denis hat außer seinen schriftstellerischenVerdiensten noch ein besonderes Verdienst umWien. Die neuern Wienerischen guten Dichter, und die aufs künftige Hoffnung geben, haben sich meistens unter seiner Anführung und Ermunterung gebildet. ${ }^{\text {"72 Die }}$ institutionsgeschichtliche und praxeologische Revision seines literarischen Projekts am Theresianum zeigt, dass mit den Juvenilia als literaturdidaktischer Inkubationsgattung und mit dem Publikationsformat der Jugendfrüchte, das auf das wichtigste regionale Publikationsmedium weltlicher Gedichte ab dem Ende der 1770er Jahre - den Wienerischen Musenalmanach - vorausweist, ${ }^{73}$ die Aneignung, Etablierung und Vervielfältigung literarischer Gattungsoptionen um 1770 Form gewinnt. Die neuen Möglichkeiten werden von einer jungen Schriftstellergeneration umfassend genutzt und weiterentwickelt. ${ }^{74}$ Für die Zeit um 1800 ließe sich aus Widmungen, Motti, intertextuellen Verweisen und literarischen Kooperationen ein Netzwerk literarischer Akteure aufstellen, das auch außerhalb der Mauern des Kollegiums an einer neuen deutschsprachigen Literatur in Österreich weiterarbeitete.

71 „Nekrolog. Michael Denis., in: Der Neue Teutsche Merkur. Vom Jahre 180o, Bd. 3, S. 227-231, hier S. 228.

72 Nicolai, Beschreibung einer Reise (Anm. 3), S. 786.

73 Vgl. York-Gothart Mix, Die deutschen Musen-Almanache des 18. Jahrhunderts, München: Beck 1987, S. 64 .

74 Für Namen und Texte vgl. Hofmann-Wellenhof, Michael Denis (Anm. 9), S. 351-359. Prominent zu nennen ist Joseph Friedrich von Retzer, der als Meisterschüler von Denis gilt, dessen Nachlass herausgibt und u.a. eine Sammlung eigener Gedichte aus dem k. $k$. Theresianum (Wien: Kurzböck 1774) veröffentlicht sowie eine sechsbändige Choice of the best poetical pieces of the most eminent English Poets (Wien: Sonnleithner und Hoerling/ Trattner 1783-1786). Das angedeutete Netzwerk geht über das von der Forschung bislang akzentuierte ,Bardenparadigma' hinaus. Vgl. zu den österreichischen Barden Annika Hildebrandt, „Von Barde zu Barde. Die Wiener Aufklärung in Michael Denis' Topographie der deutschen Literatur", in: Annika Hildebrandt, Charlotte Kurbjuhn und Steffen Martus (Hrsg.), Topographien der Antike in der literarischen Aufklärung, Bern u.a.: Lang 2016, S. 201-215, insb. S. 203-209; sowie Wolf Gerhard Schmidt, ,Homer des Nordens' und ,Mutter der Romantik: James Macphersons Ossian und seine Rezeption in der deutschsprachigen Literatur, Bd. 1: James Macphersons Ossian, zeitgenössische Diskurse und die Frühphase der deutschen Rezeption, Berlin, New York: de Gruyter 2003, S. 545-569 und S. 581-587. 